\title{
Transumbilical single-incision laparoscopic inguinal hernia repair - feasibility study on anatomical specimens
}

\author{
Andreas Kirschniak ${ }^{1,2}$, Thomas Shiozawa², Markus Küper², Frank A. Granderath ${ }^{1}$ \\ 1Department of General and Visceral and Minimally Invasive Surgery, Hospital Neuwerk, Moenchengladbach, Germany \\ 2Department of General, Visceral and Transplantation Surgery, University Hospital Tübingen, Germany \\ ${ }^{3}$ Anatomical Institute, Department of Clinical Anatomy, Tübingen, Germany
}

Videosurgery and other miniinvasive techniques 2010; 5 (2): 72-75 DOI: $10.5114 /$ wiitm.2010.14208

\begin{abstract}
Laparoscopic inguinal hernia has replaced open surgery in recent years. For transabdominal preperitoneal mesh placement, 3 incisions have to be made to prepare the inguinal region, place the mesh and adapt the peritoneum with a suture. We describe the feasibility of a single incision transumbilical hernia repair. For this, we operated on 3 anatomical specimens (2 male, 1 female), which had been conserved using alcohol-glycerol fixation. A subumbilical $1.5 \mathrm{~cm}$ incision was performed, and three $5 \mathrm{~mm}$ trocars were inserted. The preparation and procedure steps conformed to conventional laparoscopic transabdominal preperitoneal hernia repair (TAPP). In the right port we used a $5 \mathrm{~mm}$ 30 degree laparoscope, for preparation a grasper and scissors with optional flexure. Mean procedure time was $45.5 \mathrm{~min}$ (35-55 min, $\pm 7 \mathrm{~min})$. The left and right inguinal region was prepared. Adaptation in handling and ergonomics needs familiarization.
\end{abstract}

Key words: single-incision surgery, natural orifice transluminal endoscopic surgery, inguinal hernia repair.

\section{Introduction}

With the beginning of the natural orifice transluminal endoscopic surgery (NOTES) era, a new spirit came into the scientific world, inventing new approaches to the abdominal cavity and reducing incisions through the abdominal wall. With this technique it is assumed that less postoperative pain, faster recovery and reduced abdominal scarring can be achieved [1]. For this, organs such as the vagina [2-4], the colon [5] or the stomach [6, 7] are penetrated.

However, development in this area remains static. Only transvaginal cholecystectomy seems to be entering clinical practice. Reasons for this are damage to healthy hollow organs, deficit of sufficient and secure closure of the lesions, contamination of the abdominal cavity and geometrical and mechanical problems. These seem to be the reasons why newer reports deal with laparoscopic single incision procedures, reducing the skin lesions to one scar sub- or transumbilically.

In the literature different surgical procedures for different indications are described. First of all, cholecystectomy was established. After that, some reports described sigmoid resections, sleeve gastrectomies, appendicectomies, adrenalectomies and other procedures. Concerning single incision inguinal hernia repair, the first clinical cases could be found which describe a single incision total extraperitoneal hernia repair [8-13]. Two clinical case reports could be found 


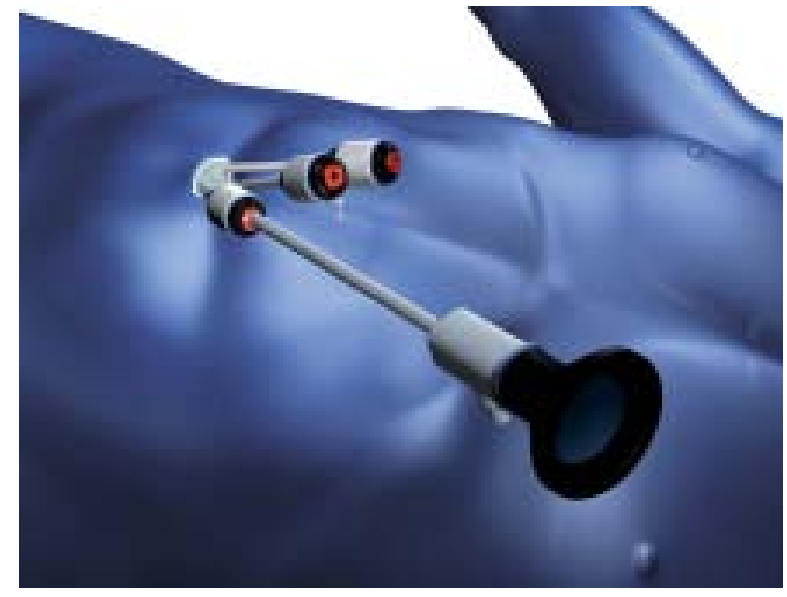

Figure 1. Instrument setting for inguinal repair on the right side

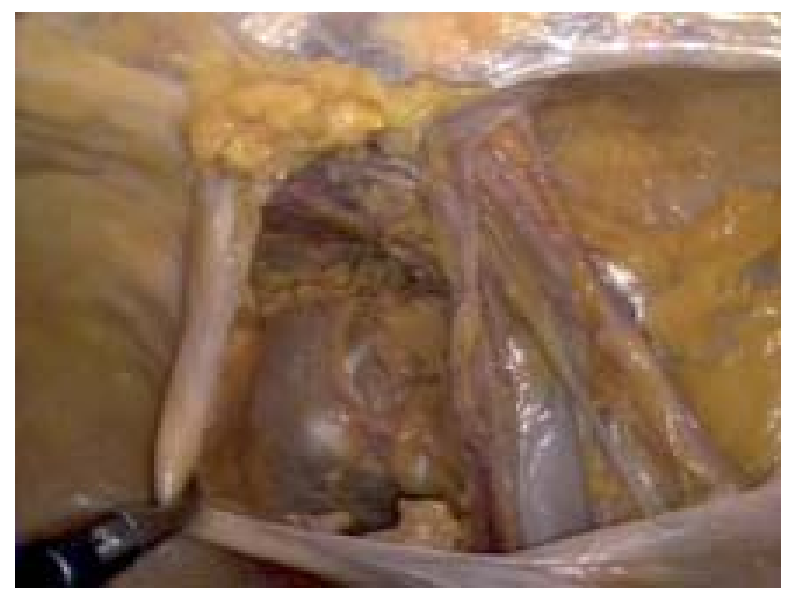

Figure 3. Prepared inguinal region

which describe transabdominal laparoscopic hernia repair using a special port system $[14,15]$.

We describe the technical feasibility of laparoscopic single incision transabdominal preperitoneal hernioplasty (TAPP) using one $15 \mathrm{~mm}$ subumbilical skin incision and three $5 \mathrm{~mm}$ trocars. This study was performed on anatomical specimens.

\section{Case report}

With respect to ethical considerations we prepared three human cadavers (79-95 years, 2 male, 1 female) donated for research and medical education to the Institute of Anatomy, University of Tuebingen. The cadavers were preserved with alcohol-glyc-

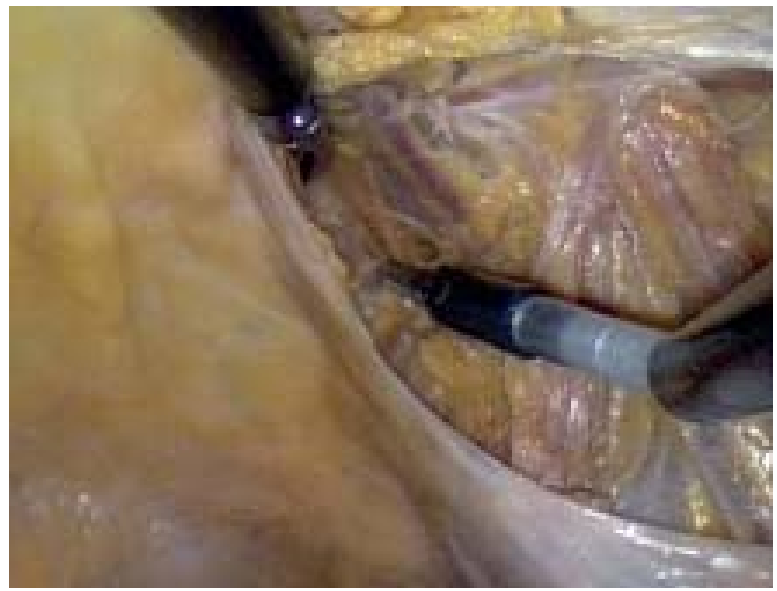

Figure 2. Preparation of the medial compartment of the right inguinal region

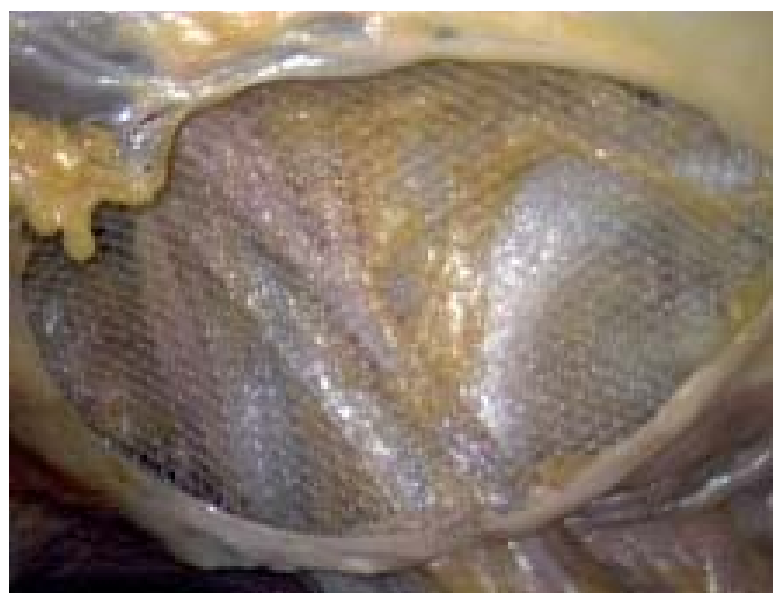

Figure 4. Placing the mesh

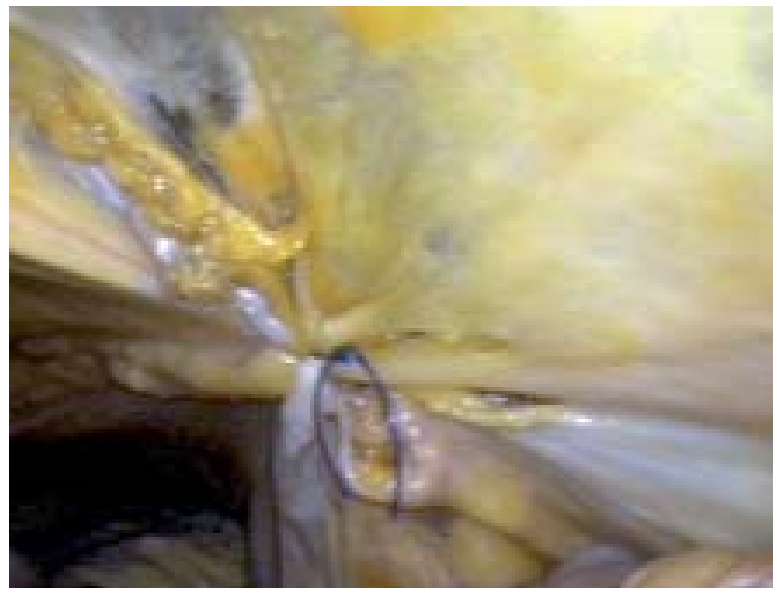

Figure 5. After suturing the peritoneum 
erol and stored air tightly under refrigerated conditions $\left(8^{\circ} \mathrm{C}\right)$. Fixation allows the preservation of tissue properties [16].

For laparoscopy we used standard laparoscopic equipment (Karl Storz, Tuttlingen, Stuttgart). Three trocars with a working channel of $5 \mathrm{~mm}$ and one trocar with a working channel of $10 \mathrm{~mm}$ were used, which replaces one $5 \mathrm{~mm}$ trocar during the procedure. For visualisation, a $5 \mathrm{~mm}$ laparoscope with 30 degree angle was used. As instruments for preparation, we used rotatable arcuated instruments (Covidien, USA).

The relevant steps of laparoscopic transumbilical single incision preperitoneal hernioplasty are adapted to transabdominal preperitoneal hernioplasty (TAPP). After positioning in a head-down position an approximately $15 \mathrm{~mm}$ long subumbilical skin incision is performed. After that, we insert the Veress needle and establish a pneumoperitoneum. The trocars are set separately through the abdominal wall in a triangular setting. The medial one is placed cranially, and the lateral two $5 \mathrm{~mm}$ trocars are set caudally (Figure 1). The laparoscope is inserted into one lateral trocar, opposite to the prepared site.

The grasping instrument is inserted through the left trocar, and the scissors through the right port.

The peritoneum is cut and the preperitoneal fat tissue is prepared (Figure 2). The inguinal region is prepared analogously to the TAPP procedure. In preparing the medial region and the symphysis, the arcuated instruments are used (Figure 3). After finishing the preparation, the right $5 \mathrm{~mm}$ trocar is changed to a $10 \mathrm{~mm}$ trocar and the prostheses can be inserted when used (Figure 4). The mesh is fixed using a protac ${ }^{\circledR}$ device. The peritoneum could be adapted using prolene 2/0 running suture (Figure 5).

All procedures could be finished and the steps described could be finished. The procedure time was $45.5 \mathrm{~min}$ on average (35-55 $\mathrm{min}, \pm 7 \mathrm{~min}$ ).

\section{Discussion}

Single incision laparoscopic hernia repair seems to be possible and feasible using available laparoscopic instruments. However, from an ergonomic point of view, there is need for improvement for it to become established in clinical practice.

The anatomical specimen, apart from computer simulation, is the only model for simulating procedures in the inguinal region. However, the prepared specimen had no relevant inguinal hernia and the results must be interpreted from this point of view.

Using only one skin incision for laparoscopic surgery, one has to distance oneself from the triangulation idea. The instruments are inserted parallel to the abdominal cavity. In our opinion, the arcuated instruments help in preparation.

Different accesses are described in the literature. Most single incision procedures are performed using a single port with three separate trocars. We used three $5 \mathrm{~mm}$ trocars inserted separately through the fascia into the abdominal cavity. At the end of the procedure we changed one $5 \mathrm{~mm}$ trocar to a $10 \mathrm{~mm}$ port for inserting the mesh. With this procedure, only small lesions into the fascia are necessary. A large facia lesion is avoided.

Dr. Andreas Kirschniak, Dr. Thomas Shiozawa, Dr. Markus Küper and Prof. Dr. Frank Granderath have no conflicts of interest or financial ties to disclose.

\section{References}

1. Nguyen NT, Reavis KM, Hinojosa MW, et al. Laparoscopic transumbilical cholecystectomy without visible abdominal scars. J Gastrointest Surg 2009; 13: 1125-8.

2. Marescaux J, Dallemagne B, Perretta S, et al. Surgery without scars: report of transluminal cholecystectomy in a human being. Arch Surg 2007; 142: 823-6.

3. Zornig C, Emmermann A, von Waldenfels HA, Mofid H. Laparoscopic cholecystectomy without visible scar: combined transvaginal and transumbilical approach. Endoscopy 2007; 39: 913-5.

4. Zornig C, Mofid H, Emmermann A, et al. Scarless cholecystectomy with combined transvaginal and transumbilical approach in a series of 20 patients. Surg Endosc 2008; 22: 1427-9.

5. Pai RD, Fong DG, Bundga ME, et al. Transcolonic endoscopic cholecystectomy: a NOTES survival study in a porcine model (with video). Gastrointest Endosc 2006; 64: 428-34.

6. Perretta S, Dallemagne B, Coumaros D, Marescaux J. Natural orifice transluminal endoscopic surgery: transgastric cholecystectomy in a survival porcine model. Surg Endosc 2008; 22: 1126-30.

7. Simopoulos C, Kouklakis G, Zezos P, et al. Peroral transgastric endoscopic procedures in pigs: feasibility, survival, questionings, and pitfalls. Surg Endosc 2009; 23: 394-402.

8. Surgit O. Single-incision laparoscopic surgery for total extraperitoneal repair of inguinal hernias in 23 patients. Surg Laparosc Endosc Percutan Tech 2010; 20: 114-8.

9. Cugura JF, Kirac I, Kulis T, et al. First case of single incision laparoscopic surgery for totally extraperitoneal inguinal hernia repair. Acta Clin Croat 2008; 47: 249-52.

10. Filipovic-Cugura J, Kirac I, Kulis T, et al. Single-incision laparoscopic surgery (SILS) for totally extraperitoneal (TEP) inguinal hernia repair: first case. Surg Endosc 2009; 23: 920-1. 
11. Bucher P, Pugin F, Morel P. Single port totally extraperitoneal laparoscopic inguinal hernia repair: Re: Single incision total extraperitoneal (one SITE) laparoscopic inguinal hernia repair using a single access port device. Jacob BP, et al. (2009) Hernia, June 27 (Epub ahead of print). Hernia 2009; 13: 667-8.

12. Jacob BP, Tong W, Reiner M, et al. Single incision total extraperitoneal (one SITE) laparoscopic inguinal hernia repair using a single access port device. Hernia 2009; 13: 571-2.

13. Agrawal S, Shaw A, Soon Y. Single-port laparoscopic totally extraperitoneal inguinal hernia repair with the TriPort system: initial experience. Surg Endosc 2010; 24: 952-6.

14. Kroh M, Rosenblatt S. Single-port, laparoscopic cholecystectomy and inguinal hernia repair: first clinical report of a new device. J Laparoendosc Adv Surg Tech A 2009; 19: 215-7.

15. Menenakos C, Kilian M, Hartmann J. Single-port access in laparoscopic bilateral inguinal hernia repair: first clinical report of a novel technique. Hernia 2010; 14: 309-12.

16. Kirschniak A, Schmidt T, Wiedemann M, et al. Development, evaluation and training of mediacal techniques on anatomical specimens. Biomedizin Tech 2004; 49 Suppl 2: 2. 